treated, and $27 \%$ (33) were biological false positives. Those with untreated STS-median age 30 (IOR 26-35); ethnicity: 45\% (20) black African, 23\% (10) black Caribbean, 18\% (8) white other, 9\% (4) Asian, 2\% (1) black British, 2\% (1) white British. All women attended the GU clinic for treatment and follow-up; with one exception who remained untreated (late latent STS) and was repatriated prior to delivery to Uganda in 2004. GU screens identified Chlamydia (3), TV (2), warts (2), herpes (1), BV (6), thrush (5) and hepatitis B (4) in those with untreated STS.

Discussion Our innovative MDT approach where each positive antenatal STS result is managed by our GU team has resulted in prompt treatment of untreated cases, identification of untreated STIs, and no reported cases of congenital STS. Our effective robust pathway includes standardised communication with all relevant teams and we encourage its use nationally.

\section{P127 AN AUDIT OF THE MANAGEMENT OF COMPLAINANTS OF SEXUAL ASSAULT COMPARED WITH THE BRITISH ASSOCIATION FOR SEXUAL HEALTH AND HIV (BASHH) 2011 GUIDELINES}

doi:10.1136/sextrans-2012-050601c.127

M McGranahan, ${ }^{*}$ N Gupta, P Goold. Whittall Street Clinic, Birmingham, UK

Background The revised BASHH guidelines for the management of sexual assault were published in 2011. Introduction of a new electronic patient record (EPR) at a sexual health clinic provided an opportunity to audit the management of sexual assault.

Aims To review the clinical care of complainants of sexual assault against the auditable outcome measures identified in the guidelines. Methods The EPR of patients attending between 1 August 2010 and 31 July 2011 was searched using the term "assault." Cases reporting a sexual assault for the first time were included and reviewed against the auditable outcome measures. Demographic data and sexually transmitted infection (STI) test results were recorded.

Results 236 records were identified but 99 cases fulfilled the inclusion criteria. Of the 14 auditable outcomes, only HIV risk assessment reached the 100\% standard and seven achieved above $60 \%$ concordance (offer and provision of HIV post-exposure prophylaxis, emergency contraception, follow-up tests, forensic medical examination, hepatitis $B$ vaccine and detailed history of assault). Child protection assessment was documented in $57 \%$ of under- 19 s. $28 \%$ had the recommended STI tests and $16 \%$ were offered STI prophylaxis. There were no self-harm risk assessments documented. STI prevalence was: Gonorrhoea 8\%, Chlamydia 9\%, HIV 2\%, Hepatitis C Virus and Trichomonas 1\%.

Conclusion Low STI testing rates overall are explained by Hepatitis $\mathrm{B}$ and $\mathrm{C}$ testing not previously being a requirement unless there was a specific risk identified. The clinic conducts an automatic risk assessment for under-16s but not for under 19s. STI prevalence was high. A sexual assault pro-forma will be recommended and improved documentation is required.

\section{P128 THE ACCEPTABILITY OF USING SOCCER CLUBS AS VENUES FOR CHLAMYDIA SCREENING IN YOUNG MEN: RESULTS FROM A QUALITATIVE STUDY}

doi:10.1136/sextrans-2012-050601c.128

\begin{abstract}
1J M Saunders, ${ }^{*}{ }^{1} \mathrm{~L}$ J Sutcliffe, ${ }^{2} \mathrm{G}$ J Hart, ${ }^{1} \mathrm{C}$ S Estcourt. ${ }^{1}$ Blizard Institute, Centre for Immunology \& Infectious Disease, Queen Mary University of London, London, UK; ${ }^{2}$ Centre for Sexual Health and HIV Research, University College London, London, UK
\end{abstract}

Background Many non-clinical, including sports, settings have been used in an attempt to screen more men for Chlamydia. While feasible there is very little research exploring their acceptability among users of these settings.

Objective We explored the acceptability of, and the best way to deliver, Chlamydia screening in soccer clubs among young men who play amateur soccer.

Methods 18 semi-structured, face-to-face interviews with men aged between 18 and 35 who play soccer in London-based non-professional leagues. Interviews were carried out from October to December 2011 and analysed using a framework approach.

Results Soccer clubs are acceptable venues to access Chlamydia screening because they offer several potential benefits over screening in traditional settings. Importantly they are discreet testing venues and allow screening to take place within the context of normal daily routines. Having testing kits handed out to all team members by a senior member of the club (captain/coach/manager) or a visiting health care professional (HCP) meant that no one would feel singled out for testing and overcome barriers to asking for, or collecting a kit from central collection points. While some men preferred to use the test kit there and then and return samples to a collection point at the club, others preferred to use kits at home and return samples to the laboratory by post. However, concerns about confidentiality and test tampering meant that some men favoured a visiting HCP to coordinate testing rather than a member of the club.

Conclusion Soccer clubs appear to be acceptable venues for young men who play soccer to access self-collected testing kits for Chlamydia. Processes for accessing, using and returning test kits should be discreet, easy and quick. We will be developing testing pathways in soccer clubs to pilot in six London clubs during the 2012-2013 season.

\section{P129 IMPROVING CLINICAL STANDARDS IN GU MEDICINE: A RETROSPECTIVE AUDIT OF NEISSERIA GONORRHOEAE}

doi:10.1136/sextrans-2012-050601c.129

S R Sharp, S Allan. * Coventry and Warickshire Hospital, Coventry, UK

Objectives This was a retrospective analysis of clinic performance in the management and treatment of Neisseria gonorrhoeae (GC) according to BASHH guidelines

Methods All cases of GC diagnosed at our clinic between 1 January and 30 June 2011 were identified. The case notes were reviewed and assessed against current BASHH criteria. This was compared to data collected in the same clinic from 1 January to 30 June in 2007, 2008 and 2009. The number of cases identified for 2007, 2008, 2009 and 2011 was 41, 61, 78 and 75 respectively.

\section{Results}

\begin{tabular}{|c|c|c|c|c|}
\hline Criterion & $2007(\%)$ & $2008(\%)$ & $2009(\%)$ & $2011(\%)$ \\
\hline $\begin{array}{l}\text { CR } 1>95 \% \text { of genital GC cases should be } \\
\text { cured by first line therapy }\end{array}$ & 77 & 96 & 100 & 97 \\
\hline $\begin{array}{l}\text { CR2 100\% patients with GC should } \\
\text { be screened for Chlamydia trachomatis or } \\
\text { receive presumptive treatment }\end{array}$ & 100 & 100 & 100 & 98.6 \\
\hline $\begin{array}{l}\text { CR3 } 100 \% \text { patients should have at least } \\
\text { one documented interview with a partner } \\
\text { notification trained health professional }\end{array}$ & 82 & 95 & 92 & 92 \\
\hline $\begin{array}{l}\text { CR4 } 100 \% \text { patients identified should } \\
\text { receive written information about STI's } \\
\text { and their prevention }\end{array}$ & 32 & 64 & 81 & 61 \\
\hline $\begin{array}{l}\text { CR5 } 100 \% \text { treated patients should have } \\
\text { a test of cure (TOC) }\end{array}$ & - & - & - & 36 \\
\hline $\begin{array}{l}\text { CR6 For each case at least } 0.6 \text { sexual } \\
\text { partners should be verified as having been } \\
\text { satisfactorily managed within } 4 \text { weeks }\end{array}$ & 0.41 & 0.33 & 0.36 & 0.5 \\
\hline
\end{tabular}

